\title{
The Perceptions of the Malaysian Professional on Emotions in Decision-Making Processes
}

\author{
Habibie Ibrahim ${ }^{1}$, Sally Johnson ${ }^{2}$ and Philip Gilligan ${ }^{3}$ \\ Universiti Malaysia Sabah ${ }^{1}$ \\ University of Bradford, England ${ }^{2,3}$
}

\begin{abstract}
The present research aimed to investigate the perceptions of the Malaysian Child Social Workers on emotions in their professional practice i.e. decision-making processes. Traditionally, decision making is viewed as a rational process where reason indicates the best way to achieve a goal. However, many philosophers, neuroscientists and psychologists emphasise that the role of emotions in decision making is not exempted. The overall research strategy was ethnographic. The researchers used a mixture of methods including individual interviews, participant observation, and a questionnaire. The research was conducted in three locations in Malaysia: Kuala Lumpur, Petaling and Kota Kinabalu. Participants consisted of child protectors and rehabilitation officers from the Malaysia Welfare Department and medical social workers in hospitals. This paper presents an analysis of individual interviews in the three locations. A total of twenty-five interviews were conducted (twelve male, thirteen female; age range 29-51). Data were analysed using thematic analysis (Braun $\&$ Clarke, 2006). The research findings revealed that the Malaysian child social workers tended to avoid emotions in their professional practice (i.e. decision-making processes), which might be due to the procedural practice. Based on the participants' perceptions with regard to the use of emotions in decision-making proceses, the Malaysian child social workers' understanding, knowledge and terms pertaining to emotions and their contributions in decision making were seemingly confined to the negative effects of emotions. Emotions, however, were not only characterised as disruptive but also viewed as having their 'rationality'.
\end{abstract}

Keywords: Emotions, decision-making processes, child and family workers, human service organisations.

\section{Introduction}

Decision making is one of the core tasks in social work practice. Child and family social workers routinely make decisions which affect clients' lives. In this case, social workers are required to make a good decision that suits the clients' desires and needs. Working with children and their families requires the social workers to address the parents' needs, as well as those of the children as both parties often require attention. When social workers begin to think about children, they may be confronted with dilemmas. For instance, social workers have to focus on the children's needs whilst attending simultaneously to the families' circumstances in which they are located (Wilson, Ruch, Lymbery \& Cooper 2008). Power is one of the principles of effective relationship-based social work with children and families. Wilson et al. (2008) argue that one of the main reasons emotions run so high in social work with children and families relates to the statutory responsibilities of childcare social workers, which allow them under certain circumstances to remove children from their families.

Some researchers have viewed emotions as a dimension in decision making (see Damasio, 2006; DeSousa, 1987). There seem to be situations in which emotions can enhance decision-making processes even though it is widely believed that the influence of emotions on reasoning would create problem. The researcher posits that whether emotions are functional or dysfunctional for decision making, this depends on how social workers experience their emotions and what they do about them during decision making.

This paper explores Malaysian child social workers' perceptions about emotions and their contributions in decision-making processes in the context of child and family social work in Malaysia. 


\section{Methodology}

Empirical investigations in psychology suggest that some emotions can be found in all cultures, and there are expressions that can be cross-culturally recognised (see Brun, Doguoglu \& Kuenzle, 2008). This research employed the ethnographic approach as the research design. However, this research was not conducted as a full ethnography. This research draws on and is framed by some ideas which originate from ethnography. The way in which the ethnographic approach was used was due to the philosophical stance of the researcher (see Atkinson \& Hammersley, 1994), in which emotion is perceived as a confluence of biological underpinnings, shaped by a cultural worldview and script for social behaviour.

The complex nature of the main research question seeks to investigate the perceptions of the Malaysian child social workers concerning emotions and its contributions in the processes of decision making in child protection, child rehabilitation and child welfare organisations. Individual interviews were used to provide the qualitative data that aimed at gaining a working familiarity with the frames of meaning within which the child social workers perceived and used emotions and in their professional practice. Data then coded and analysed manually. The data were analysed utilising thematic analysis, which searched for themes and patterns as developed by Braun and Clarke (2006). More specifically, the taped interviews were transcribed.

The data were collected from the volunteered male and female social workers, experienced and newly qualified social workers, people of different age groups, levels of education, and lengths of service in their current jobs, and individuals working in a variety of roles (e.g. as a child protector, a child rehabilitation officer or/and an administrator). Table 1 presents the socio-demographic descriptions of the participants/interviewees. The mean age of the participants was 38 years, comprising 12 (48\%) male and 13 (52\%) female participants. From the 25 participants, one reported as unmarried. In terms of educational background, the participants were divided into three formal educational levels: 6 participants (24\%) had a diploma certificate, 15 participants $(60 \%)$ possessed a bachelor's degree and 4 participants (16\%) having a master's degree. On the other hand, in terms of working profession, 8 participants (32\%) were child protectors, 10 participants (40\%) were probation officers and 7 participants (28\%) were medical social workers. Conversely, 11 (44\%) interviews were conducted in Kota Kinabalu, 10 (40\%) interviews in Kuala Lumpur, and 4 (16\%) interviews in Petaling. Meanwhile, the social workers' working experiences ranged from 1 year to more than 20 years. 
Table 1: Participants' Demographic Information (Individual Interviews)

\begin{tabular}{|c|c|c|c|c|c|c|c|}
\hline Pseudonym & Gender & Age & $\begin{array}{l}\text { Marital } \\
\text { Status }\end{array}$ & $\begin{array}{c}\text { Academic } \\
\text { Qualification }\end{array}$ & Position & Location & $\begin{array}{l}\text { Experiences in Child } \\
\text { (Years) }\end{array}$ \\
\hline Child protector 1 & Male & 35 & Married & Diploma & Child Protector & Kota Kinabalu & 3 years \\
\hline Probation officer 1 & Female & 35 & Married & Diploma & Probation Officer & Kota Kinabalu & 2 years \\
\hline Probation officer 2 & Female & 35 & Married & Bachelor & Probation Officer & Kota Kinabalu & 5 years \\
\hline Probation officer 3 & Male & 32 & Married & Diploma & Probation Officer & Kota Kinabalu & 2 years \\
\hline Probation officer 4 & Male & 47 & Married & Bachelor & Probation Officer & Kota Kinabalu & 5 years \\
\hline Child protector 2 & Female & 33 & Married & Diploma & Child Protector & Kota Kinabalu & 2 years \\
\hline Child protector 3 & Female & 40 & Married & Bachelor & Child Protector & Kota Kinabalu & 19 years \\
\hline Child protector 4 & Female & 48 & Married & Master & Child Protector & Kota Kinabalu & $>20$ years \\
\hline Child protector 5 & Male & 34 & Married & Diploma & Child Protector & Kota Kinabalu & 5 years \\
\hline Med Soc Worker 1 & Female & 43 & Married & Bachelor & Med Social Worker & Kuala Lumpur & 2 years \\
\hline Med Soc Worker 2 & Male & 51 & Married & Bachelor & Med Social Worker & Kuala Lumpur & $>20$ years \\
\hline Probation officer 5 & Male & 45 & Married & Diploma & Probation Officer & Kuala Lumpur & 16 years \\
\hline Child protector 6 & Female & 35 & Married & Bachelor & Child Protector & Kuala Lumpur & 5 years \\
\hline Med Soc Worker 3 & Female & 50 & Married & Master & Med Social Worker & Kuala Lumpur & $>20$ years \\
\hline Probation officer 6 & Female & 36 & Married & Master & Probation Officer & Kuala Lumpur & 5 years \\
\hline Probation officer 7 & Female & 30 & Married & Bachelor & Probation Officer & Petaling & 4 years \\
\hline Probation officer 8 & Male & 29 & Married & Bachelor & Probation Officer & Petaling & 2 years \\
\hline Child protector 7 & Female & 34 & Married & Bachelor & Child Protector & Petaling & 9 years \\
\hline Child protector 8 & Male & 39 & Married & Bachelor & Child Protector & Kuala Lumpur & 5 years \\
\hline Probation officer 9 & Male & 29 & Married & Bachelor & Probation Officer & Petaling & 1 year \\
\hline Probation officer 10 & Female & 34 & Married & Bachelor & Probation Officer & Kuala Lumpur & 1 year \\
\hline Med Soc Worker 4 & Male & 33 & Married & Bachelor & Med Social Worker & Kuala Lumpur & 5 years \\
\hline Med Soc Worker 5 & Male & 42 & Single & Master & Med Social Worker & Kuala Lumpur & 6 years \\
\hline Med Soc Worker 6 & Male & 33 & Married & Bachelor & Med Social Worker & Kota Kinabalu & 9 years \\
\hline Med Soc Worker 7 & Female & 37 & Married & Bachelor & Med Social Worker & Kota Kinabalu & 13 years \\
\hline
\end{tabular}




\section{Findings And Discussions}

\section{Emotions as a Negative and Disruptive Element in Decision-making Processes}

The theme - 'The perception of emotions as a negative and disruptive element in the processes of making decisions' has been identified while investigating how the Malaysian social workers perceived emotions and EI in decision-making processes. The participants seemed to perceive emotions as a negative element and commented that emotions and feelings need to be avoided during professional practice, such as in the process of making decisions. They perceived that emotions could disrupt decision-making processes. The participants mentioned:

"In management, we can't be emotional. It must depend on the needs, rationale and our experiences. So people will not say ... 'Eh! Emotions have been involved in their decision making'. It must be natural."

\section{(Child Protector 4, female, aged 48)}

"Whatever kind of decision, it must be on the professional basis, you know. We do not only follow our emotions or feelings, be it anger, patriotism, love for our work or elements of bias. It's not only for the benefits of our services or our department. Instead, when we refer to our services, we are usually focused more on the patients' benefits because our core business is to serve the patients."

(Medical Social Worker 3, female, aged 50)

"Emotions, if emotions ... errr ... I don't involve emotions in making decision. For example, if a mother has to be sent to prison and she has a child aged about five years old, when the child turns 5, they need to be separated. For the child's sake, we don't allow a child to be in prison. There are emotions. Of course, a child must be taken care by his/her mother. But in this case, it's different."

\section{(Child Protector 8, male, aged 39)}

"I am not saying that they [emotions] are negative, but I don't want emotions to influence my decision-making process, and I am not saying that if I use emotions, my decision would be a wise one. I just don't want to be influenced by my emotions."

(Probation Officer 7, female, aged 30)

The illustrations above seem to show us that emotions were perceived by the Malaysian social workers as a negative element, and thus, should be avoided in social work practice (i.e. decision-making processes), regardless of whether they were viewed as positive or negative. This seems to suggest that, if one includes emotions in decision-making processes, he or she will be viewed as unprofessional. In addition, the interest of the clients must be made a priority. Even though social workers may experience a certain kind of emotion when dealing with clients, they must avoid it at all costs. This seems to reveal that in the Malaysian context and social work practice particularly, emotions (i.e. one's and others' emotions) are avoided and that their inclusion in professional practice is discouraged. This may result from the general view that emotions are disruptive; due to this perception, emotions (i.e. anger) are devalued in some cultures (see Mesquita \& Walker, 2003).

The reason behind the avoidance of emotions in professional practice as perceived by the participants was that emotions could disrupt their rational thinking regardless of whether they are positive or negative. The participants claimed that involvement of certain kinds of emotions could make them lose their confidence and be 
doubtful in making a wise judgement. Hence, according to them, emotions should be used with a limit. The participants reported:

"For me, I do not involve emotions. In the process of making decisions, sometimes, we can feel a mixture of emotions whether for good mood, bad mood or personal problems. In decision making, I would not be confident. Sometimes, I would be doubtful too. If emotions are there, they would make me less focused on my work, for example, if I have personal problems or any internal or external problems, of course, they [negative emotions] will disturb me. I would not make wise decisions if I'm being emotional."

(Child Protector 5, male, aged 34)

"I think we need to minimise the use of our emotions. I think if we depend on emotions, any kind of decision that relates to the patients will not be a wise one."

(Medical Social Worker 7, female, aged 37)

The illustrations above show that the inclusion of in decision-making processes is not encouraged due to their negative effects on decisions and actions. The Malaysian child social workers perceived that certain emotions which arose from problems faced by individuals or issues related to clients could disrupt their rational judgement. It seems that emotions are completely avoided and rejected in their professional duties. The participants gave their comments below:

"I have a case involving a boy. This boy is sent to the rehabilitation institution due to his misbehaviour. I believe he [his client] became mischievous due to his broken family. At that time it was close to Eid celebration. He has been in the institution for 6 months. Our procedure states that after 6 months in the institution, a child can apply to go home at least 3 days for the Eid celebration or if there is any emergency in his/her family. But it depends on his/her discipline while he/she is in the institution. We don't simply allow them to go home if we're not satisfied with their behaviour. His mother came and showed her sadness and anger. I don't mind even if it is for Eid Mubarak. I know the child was sad, really sad because he wanted to be with his family. But we have our policy."

(Probation Officer 5, male, aged 45)

Traditionally, decision making is viewed as a rational process where reason indicates the best way to achieve a goal. Stocker (2002) states that one reason ethicists have ignored emotions or thought them as relatively unimportant stems from the views holding that emotions are abnormal and perhaps rare events, and often of considerable height or depth. Emotions thought of this way are naturally perceived as misleading, disrupting, and even overwhelming. Goldie and Spicer (2002) also argue that emotions are characteristically thought of by philosophers as states which give rise to perturbation in what might roughly be called right thinking.

The participants, however, seem to reveal that their work is full of emotional experiences. They experienced negative as well as positive emotions (e.g. sadness, anger, lack of confidence, doubt and empathy), particularly when dealing with clients. However, due to their negative perceptions towards emotions, particularly the emotions which had been emphasised by the management and which they had been discouraged from using in their professional practice, they preferred to put aside their emotions when doing their jobs. It seems that the Malaysian child social workers' understanding, knowledge and terms concerning emotions and their contributions in decision making were limited to the negative effects of emotions. In addition, the participants perceived that, if they included emotions in their decision-making processes, they would consider their acts as unprofessional, which would lead to unethical practice. However, this is not surprising, particularly when it concerns social work practice in which the relationship between the role of emotions within the practice is 
considered against the backdrop of proceduralist practice (see Ingram, 2012). As social workers, they have a role in supporting reasonable and informed client decisions in accordance with professional guidance, values and standards, as well as legal and policy frameworks in their practice (Taylor, 2010). The Malaysian social workers indicated that they tended to avoid emotions, which might be due to the proceduralist practice. This was in contrast with social work professionals in the UK, where the standard view has always been that social workers need to be aware of their emotions and to use emotions in a professional way that prioritises the needs of service users. As a profession, the UK's social workers are and have been highly critical and resistant to the types of proceduralist practice which governments have tried to impose on them (Ingram, 2012).

\section{Conclusion}

Under the theme - 'Perception of emotions as a negative and disruptive element in decision making processes', it seems that the Malaysian child social workers' understanding, knowledge, and terms concerning emotions and their contributions in decision making were limited to the negative effects of emotions. This may stem from how Malaysian people devalue emotions due to cultural restrictions in expressing negative emotions.

\section{Bibliography}

[1] Damasio, Descartes' Error: Emotion, Reason and Human Brain. London: Vintage, 2006

[2] Mesquita, and R. Walker, "Cultural differences in emotions: A context for interpreting emotional experience," Behavior Research and Therapy, vol. 41, pp.777-793, 2003. http://dx.doi.org/10.1016/S0005-7967(02)00189-4

[3] B.J. Taylor, Professional Decision Making in Social Work. Exeter: Learning Matters Post Qualifying Social Work Series, 2010.

[4] G. Brun, U. Doguoglu, and D. Kuenzle, Epistemology and Emotions. Cambridge, UK: Aldershot: (Ashgate), 2008.

[5] Institut Sosial Malaysia (ISM) Core services: Training. [online] Available: <http://www.ism.gov.my/default.php?page=Khidmat-Latihan

[6] K. Wilson, G. Ruch, M. Lymbery, and A. Cooper, Social Work: An Introduction to Contemporary Practice. Essex: Pearson Education Limited, 2008.

[7] M. Stocker, "Some Ways to Value Emotions," in Understanding Emotions, P. Goldie, ed Ashgate, Aldershot, UK, 2002.

[8] P. Atkinson, and M. Hammersley, "Ethnography and Participant Observation," in Handbook of Qualitative Research, N. K. Denzin, and Y.T. Lincoln, ed. London, Sage Publications, Inc, 1994.

[9] P. Goldie, and F. Spicer, "Introduction to Emotions," in Understanding Emotions, P. Goldie, ed. Ashgate, 2002, pp. 122.

[10]R. DeSousa, The Rationality of Emotion. London: The MIT Press, 1987.

[11] R. Ingram, "Locating emotional intelligence at the heart of social work practice," British Journal of Social Work, pp. 118,2012

[12] V. Braun, and V, Clarke, "Using thematic analysis in psychology," Qualitative Research in Psychology, vol.3, pp. 77101, 2006.

http://dx.doi.org/10.1191/1478088706qp063oa 